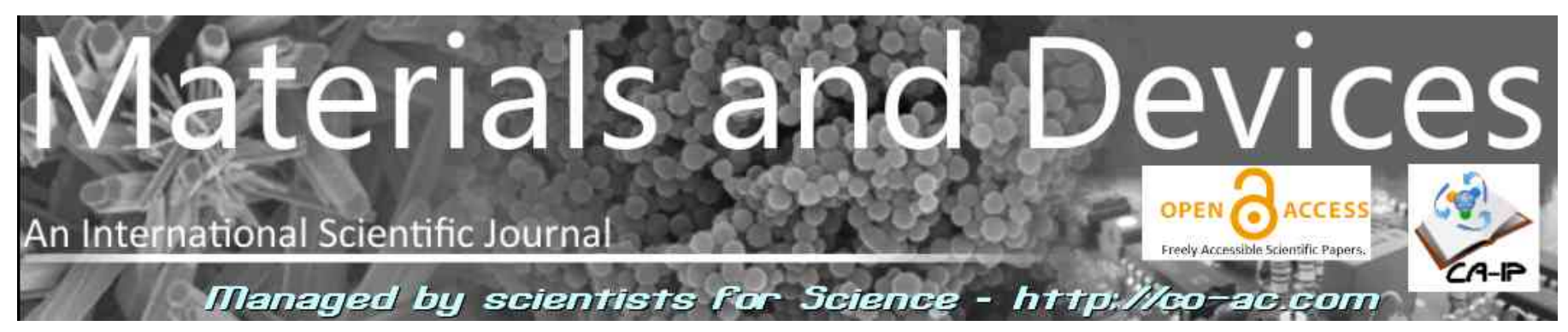

\title{
FILLING RATE DEPENDENCE ON THEORETICAL RAMAN SPECTRA OF CARBON $\mathrm{C}_{60}$ PEAPODS
}

\author{
H. Chadli, F. Fergani, S. A. Ait Abdelkader, AH Rahmani, B. Fakrach, \\ A. Rahmani \\ Laboratoire d'Etude des Matériaux Avancés et Applications (LEM2A), Université Moulay \\ Ismail, FSM-ESTM-ESTK, BP 11201, Zitoune, 50000 Meknes, Morocco.
}

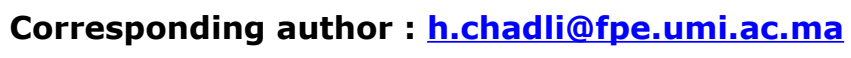

RECEIVED: 27 September 2016 / RECEIVED IN FINAL FORM: 21 December 2016 / ACCEPTED: 21 December 2016

\begin{abstract}
We use the spectral moments method in the framework of the bond-polarization theory to calculate nonresonant Raman spectra of $\mathrm{C}_{60}$ peapods as a function of the concentration of fullerenes inside the single wall carbon nanotubes. The evolution of the average Raman intensity ratios between Raman mode of $\mathrm{C}_{60}$ molecules and nanotube as a function of the concentration of fullerenes has been analyzed and a general good agreement is found between calculations and measurements.
\end{abstract}

Keywords : CARBON NANOTUBES, PEAPODS, RAMAN SPECTROSCOPY, SPECTRAL MOMENT METHOD, SIMULATION

\section{Introduction}

Single walled carbon nanotubes (SWNT) can encapsulate small and large molecules, including $\mathrm{C}_{60}$ fullerenes ${ }^{[1,2,3]}$. Those systems consist of SWNT in which fullerene molecules are inserted and called peapods. This hybrid system between fullerene and SWNT have generated a lot of interest for future electronic applications. Due to their special onedimensional nanosized structure and their tunable electronic properties, peapods are considered important materials for several potential applications from high temperature superconductor ${ }^{[4]}$ to memory elements $^{[5]}$.

From an experimental point of view, peapods structural analysis can be performed using transmission electron microscopy ${ }^{[1,2]}$ or electron diffraction ${ }^{[3]}$ X-ray scattering ${ }^{[6]}$ or using Raman spectroscopy ${ }^{[7]}$. From a theoretical point of view, it was shown that $\mathrm{C}_{60}$ molecules inside SWNTs with a wide range of diameters from $1.25 \mathrm{~nm}$ to $2.71 \mathrm{~nm}$ can form ten different packing arrangements ${ }^{[8]}$. Some of these predicted phases have been experimentally observed ${ }^{[9]}$.

Kuzmany et al. have performed a detailed Raman analysis of the concentration of $\mathrm{C}_{60}$ fullerenes in peapods $^{[7]}$. The authors measured the scattering relative intensity from the fullerenes to that from the tube in order to obtain the relative $\mathrm{C}_{60}$ filling concentrations. The relative concentrations derived from the measurement of normalized intensity ratio for each mode of $\mathrm{C}_{60}$ are close (see Table 1 of Ref. ${ }^{[7]}$ ).

In previous works ${ }^{[10,11]}$, we calculated the nonresonant Raman spectra of $\mathrm{C}_{60}$ peapods for linear and zigzag configurations. In this paper, in order to 
improve the comparison with the experimental Raman data measured on peapod samples, we calculate the nonresonant Raman spectra of $\mathrm{C}_{60}$ peapods with large diameters $(2.15-2.3 \mathrm{~nm})$ in which the $\mathrm{C}_{60}$ molecules phase can take a double helix or a two molecules layers configuration depending on the diameter. The relative intensity ratio between a Raman mode of $\mathrm{C}_{60}$ and a mode of SWCNT, normalized by the same ratio calculated for a reference filling factor, gives a useful method to derive from Raman experiments the relative concentration of $\mathrm{C}_{60}$ in peapods samples prepared with the same batch that the reference filling factor sample.

\section{Model and method}

The structure of $\mathrm{C}_{60} \mathrm{~S}$ inside SWNT depends primarily on tube diameter. We have already studied the different possible configurations of $\mathrm{C}_{60}$ inside SWCNT and found that the $\mathrm{C}_{60}$ molecules adopt a linear configuration for diameters below $1.45 \mathrm{~nm}$ and a zigzag configuration for diameters between 1.45 and $2.20 \mathrm{~nm}^{[9]}$. In this study, we consider SWNT in a diameter range from 2.20 to $2.30 \mathrm{~nm}$ in which the $\mathrm{C}_{60}$ molecules can take a double helix or a two molecules layers configuration depending on the nanotube diameter. These configurations of the $\mathrm{C}_{60}$ molecules inside the nanotubes are derived from energy minimization calculations previously described in previous works ${ }^{[10]}$. The geometrical optimizations of $\mathrm{C}_{60}$ inside SWNT are derived. We found that the $\mathrm{C}_{60}$ molecules adopt a double helix arrangement for SWNT's diameter in the range $2.16-2.23 \mathrm{~nm}$ and layers of two molecules for tube diameter in the range 2.23-2.28nm.

For the SWCNT, the C-C interactions are described using the force constant model introduced by Saito ${ }^{[12]}$. The interactions between carbon atoms for the $C_{60}$ molecules are calculated using the force constants model described by Jishi and Dresselhaus ${ }^{[13]}$. The interactions between carbon atoms belonging to two different molecules (tube-tube, $\mathrm{C}_{60}-\mathrm{C}_{60}$ or tube- $\mathrm{C}_{60}$ ) are described by the familiar (12-6) Lennard-Jones potential,

$$
U_{L J}=4 \varepsilon\left[(\sigma / r)^{12}-(\sigma / r)^{6}\right]
$$

Where $r$ is the carbon atom-atom distance, $\varepsilon=2.964$ meV and $\sigma=0.3407 \mathrm{~nm}$ are van der Waals parameters.

\section{Results}

Raman spectra calculations are based on the spectral moments method which has proved to be a powerful approach for determining the infrared, Raman, and inelastic neutron scattering spectra of harmonic systems (for mor details see Refs. ${ }^{[14]}$ ).

The calculated ZZ-polarized Raman spectra of individual peapods for each configuration of the $C_{60}$ molecules inside the tube are shown in figure 1 along with their corresponding unfilled nanotubes and the unoriented $\mathrm{C}_{60}$ molecule. In the following, we mainly discuss the polarized ZZ Raman spectra of unfilled zigzag SWNTs ( $(\mathrm{n}, 0)$ with $\mathrm{n}=17,28$ and 29), and for their corresponding peapods with linear $\left[\mathrm{C}_{60} @(17,0)\right]$, double-helix $\left[\mathrm{C}_{60} @(28,0)\right]$, and two-molecule layers phases [C60@(29,0)].

Concerning the high-wavenumber modes range, above $1200 \mathrm{~cm}^{-1}$, the main modes of $\mathrm{C}_{60}$ are located around $\left.1219\left(\mathrm{H}_{\mathrm{g}}(6)\right), 1403 \mathrm{H}_{\mathrm{g}}(7)\right), 1468\left(\mathrm{~A}_{\mathrm{g}}(2)\right)$, and $1582 \mathrm{~cm}^{-1}$ $\left.\mathrm{H}_{9}(8)\right)$, in $\mathrm{C}_{60} @(17,0), \mathrm{C}_{60} @(28,0)$, and $\mathrm{C}_{60} @(29,0)$, independently of the configuration of $\mathrm{C}_{60}$ molecules inside the tube, these modes show a small upshift (1-2 $\mathrm{cm}^{-1}$ ) with respect to their position in the free $\mathrm{C}_{60}$ spectrum. As already found in linear and zigzag peapods (see figure 2 in Ref. ${ }^{[10]}$ ), We calculate that the Tangential-Like Modes (TLM) of SCNTs are almost not affected by the insertion of $\mathrm{C}_{60}$ molecules inside the nanotube.

Concerning the main modes of $(28,0)$ and $(29,0)$ SWNT located at 168, 102 and $98 \mathrm{~cm}^{-1}$ are upshift to 174,102 and $100 \mathrm{~cm}^{-1}$, respectively. These shift and splitting of Radial Breathing-Like Modes (RBLM) depend on one side, on the configuration of the $C_{60}$ molecules inside SWNT, and the other side on the coupling effects related to the interactions between the $\mathrm{C}_{60}$ molecules and the nanotube host, and on inter- $\mathrm{C}_{60}$ interactions.

Using the spectral moments method, we investigate the evolution of the average non resonant intensity ratios between Raman mode of $\mathrm{C}_{60}$ molecules and nanotube as a function of the concentration of $\mathrm{C}_{60} \mathrm{~S}$ inside the tubes. Obviously, this non-resonant approach is not able to calculate the dependence of the absolute intensity of each mode with the excitation energies. Nevertheless, concerning the dependence of the Raman spectrum with the filling factor, the relative intensity ratio between a Raman mode of $\mathrm{C}_{60}$ and a mode of SWCNT, normalized by the same ratio calculated for a reference filling factor, gives a useful method to derive from Raman experiments the relative concentration of $\mathrm{C}_{60}$ in peapods samples prepared with the same batch than the reference filling factor sample.

We calculate the dependence of the Raman spectrum at different filling factor. To facilitate the comparison with the experimental results, we performed an average of 
the Raman spectra over the peapod orientations with regards to the laboratory frame. Raman spectra are calculated in the VV configuration for unoriented peapod samples. For each filling factor, the integrated intensity ratios between a Raman mode of $\mathrm{C}_{60}$ and the RBLM (for $\mathrm{C}_{60}$ phonon modes: $\mathrm{Hg}(2), \mathrm{Ag}(1), \mathrm{Hg}(3)$ and $\mathrm{Hg}(4)$ ) or $\mathrm{G}$-mode (for $\mathrm{C}_{60}$ phonon modes: $\mathrm{Hg}(7)$ and $\mathrm{Ag}(2))$ are calculated. These calculated intensity ratios are normalized with respect to the same intensity ratios calculated for the $60 \%$ filling factor sample. The

relative concentrations are derived by this way for the typical $\mathrm{C}_{60} @(28,0)$ (double helix chain of $\left.\mathrm{C}_{60}\right)$, $\mathrm{C}_{60} @(29,0)$ (two molecule layers), $\mathrm{C}_{60} @(13,13)$ (zigzag chain of $\mathrm{C}_{60}$ ) and $\mathrm{C}_{60} @(10,10)$ (linear chain of $\mathrm{C}_{60}$ ) (Fig. 2a, Fig.2b, Fig 2c and Fig.2d, respectively).

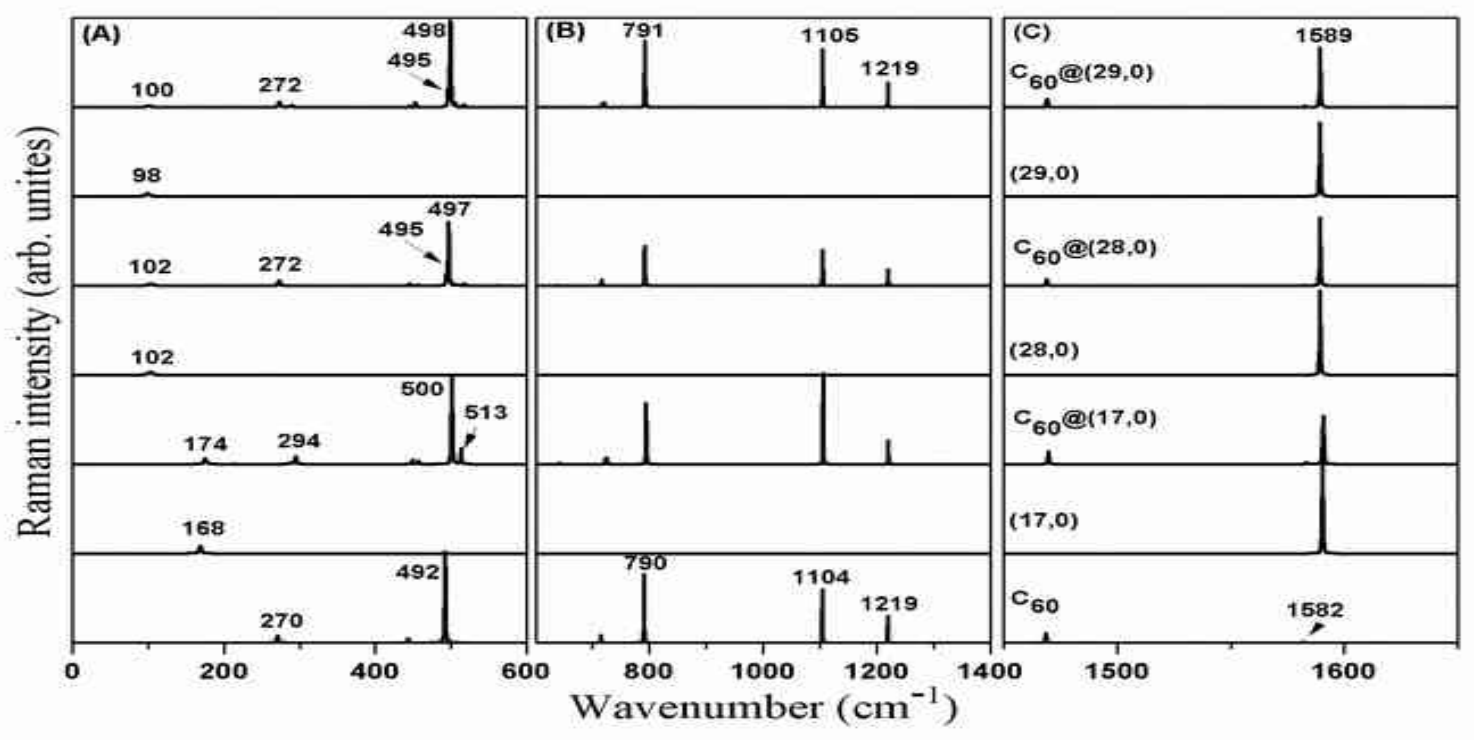

Figure 1: The $Z Z$ calculated Raman spectra of several phases of $\mathrm{C}_{60}$ inside SWNTs.

Spectra are displayed in the Breathing mode (A), intermediate (B) and TLM (C) ranges.

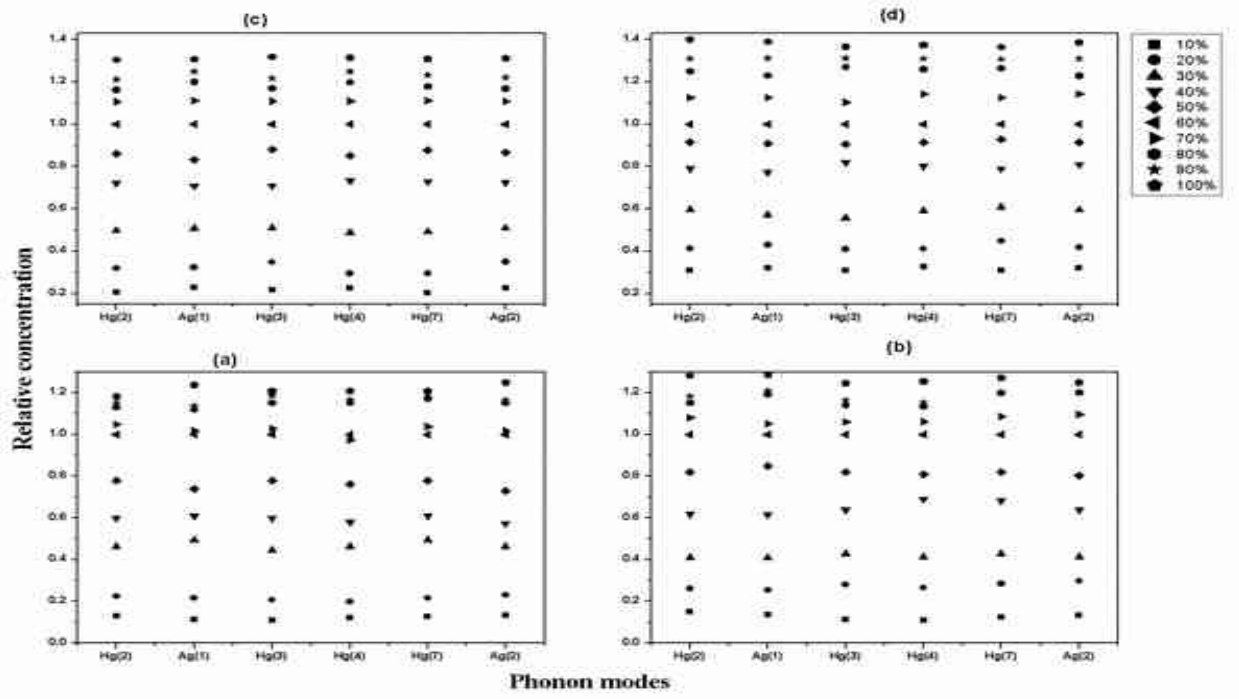

Figure 2: Calculated average intensity ratios, normalized on the $60 \%$ filling factor intensities, between modes of the $C_{60}$ in peapods crystal and the $R B L M(H g(2), A g(1), H g(3), H g(4))$ or G-mode (Ag(2)) of nanotube.

The considered configurations of $\mathrm{C}_{60}$ are linear (a), zigzag (b), double helix (c) and two-molecules layers (d) inside (10,10), $(16,16),(28,0)$ and $(29,0)$, respectively. 
As expected, for all the investigated peapods diameter, the relative concentrations calculated for each $\mathrm{C}_{60}$ mode are close. The comparison of the data of figure 2 shows that the relative concentrations calculated for infinite peapods increase when the peapod diameter increases. Indeed, for a filling factor around $20 \%$, the relative concentration is close to $0.2,0.4,0.6$ and 0.7 in $\mathrm{C}_{60} @(10,10)$ (diameter of $(10,10)$ is $1.35 \mathrm{~nm}), \quad \mathrm{C}_{60} @(13,13)$ (diameter of $(13,13)$ is $1.76 \mathrm{~nm}), \mathrm{C}_{60} @(28,0)$ (diameter of $(28,0)$ is $2.19 \mathrm{~nm}$ ) and $\mathrm{C}_{60} @(29,0)$ (diameter of $(29,0)$ is $2.27 \mathrm{~nm})$, respectively.

In the $\mathrm{C}_{60} @(10,10)$, the average relative concentrations are found between 0.98 and 1.08 following the different $\mathrm{C}_{60}$ phonons modes, in good agreement with the experimental relative concentration evaluated around $1.13^{[7]}$. For concentrations around 20\% (corresponding to the L43 sample (EELS concentration 25 210 ) in Ref. ${ }^{[7]}$ ), the average relative concentration is calculated around
$0.22 \pm 0.02$ except for $\mathrm{Ag}(2)$ mode showing an overestimated concentration, in good agreement with the experimental relative concentration evaluated around 0.19 .

\section{Conclusion}

In this work, we calculate the nonresonant Raman spectrum of isolated peapods with large diameter and using the spectral moments method. The dependence of the Raman spectrum with the $C_{60}$ filling level have been discussed. The evolution of the average intensity ratios between Raman mode of $\mathrm{C}_{60}$ molecules and nanotube as a function of the concentration of $\mathrm{C}_{60} \mathrm{~S}$ have been analyzed and $\mathrm{a}$ general good agreement is found between calculations and measurements.

\section{Acknowledgements:}

The work was supported by the CNRS-France/CNRST-Morocco agreement.

\section{REFERENCES}

1. B. W. Smith, M. Monthioux, D. E. Luzzi, Nature 396, p 323 (1998).

2. H. Kataura, Y. Kumazawa, Y. Maniwa, I. Umezu I, S. Suzuki, Y. Ohtsuka, Y. Achiba Synth. Metals 121 p.1195 (2000)

3. H. Hirahara, K. Suenaga, S. Bandow, H. Kato, T. Okazaki, H. Shinohara, S. lijima Phys. Rev. Lett. 85 p.5384 (2000)

4. R. F. Service, Science 292, p 45 (2001).

5. Y. K. Kwon, D. Tomanek, and S. lijima, Phys. Rev. Lett. 82, p 1470 (1999).

6. H. Kataura, Y. Maniwa, M. Abe, A. Fujiwara, T. Kodama, K. Kikuchi, H. Imahori, Y. Misaki, S. Suzuki, Y. Achiba, Applied Physics A 74, p 349 (2002)

7. H. Kuzmany, R. Pfeiffer, C. Kramberger, T. Pichler, X. liu, M. Knupfer, J. Fink, H. Kataura, Y. Achiba, B.W. Smith, D.E. Luzzi Appl. Phys. A 76, p.449 (2003)

8. M. Hodak, L. A. Girifalco, Phys. ReV. B 68, p 085405 (2003).

9. A. Khlobystov, D. A. Britz, A. Ardavan, G. A. D. Briggs, Phys. Rev. Lett. 92, p 245507 (2004).

10. H. Chadli, A. Rahmani, K. Sbai, P. Hermet, S. Rols, and J.-L. Sauvajol, Phys. Rev. B 74, p 205412 (2006).

11. H. Chadli, F.Fergani, M.Bentaleb, B.Fakrach, K.Sbai, A.Rahmani, J.-L.Bantignies, J.-L. Sauvajol, PhysicaE 71, p 31 (2015).

12. R. Saito, T. Takeya, T. Kimura, G. Dresselhaus, and M. S. Dresselhaus Phys. Rev. B 57 p 4145 (1998).

13. R. A. Jishi, R. M. Mirie, and M. S. Dresselhaus, Phys. Rev. B 45, p 13685 (1992).

14. A. Rahmani, J.-L. Sauvajol, S. Rols, and C. Benoit, Phys. Rev. B 66, p 125404 (2002). 